УДК 141

\title{
В.И. Миллер
}

\section{МЕТАФИЗИЧЕСКОЕ ОСМЫСЛЕНИЕ СТАНОВЛЕНИЯ КОНЦЕПЦИИ ЕСТЕСТВЕННОГО ПРАВА}

\begin{abstract}
Исследована проблема значимости концепции естественного права в социально-философской теории и практики. Предпринят анализ правовых теорий, определяющих природу и ценность естественного права. Утверждается, что становление концепции естественного права неразрывно связано с западноевропейской гуманистической традицией. Выдвигается тезис о том, что гуманизм как принцип положен в основание становления концепции естественного права.

Ключевые слова: метафизика права; концепция естественного права; гуманизм; права человека.
\end{abstract}

С развитием философского знания право стало обретать онтологическую и метафизическую обоснованность. Область научного исследования, в которой право интерпретировано через призму трансцендентных первооснов сущего и трансцендентальных априорных единиц нематериального опыта, получила название метафизики права. Это философское постижение оснований правовой системы возникло в Германии в эпоху Просвещения. Начиная с Гуго Гроция и заканчивая Джоном Локком, а также первые системы немецкого идеализма были метафизикой естественного права, которые отстаивали идеологию гуманистических прав человека, моральную и утилитарную автономию личности, гуманистическую суть права. Постулат права усматривался в справедливости, реальность права - в справедливом порядке. Тем самым право укоренялось в морали, а философские размышления о праве - в этике. Подобная этическая универсализация права сопровождалась его натурализацией, поскольку именно в устойчивой природе человека усматривались исток и тайна права, а законы природы были тождественны законам разума, на которых базировались право и мораль. Естественное право мыслилось как выведение правовых норм из определенных принципов, которые соответствовали природной сути вещей и не подлежали пересмотру.

Истоки естественного права обнаруживались в мифологических памятниках древнейших цивилизаций в виде свода правил и традиций обычного права. Одной из особенностей права того времени была неотрефлексированность, выражающаяся в том, что человек анализировал и оценивал свои поступки через призму существовавших религиозных и моральных нормативов. И.А. Покровский писал о том, что этическое чувство возникает даже на обыденном уровне применения права, выражающееся в оценке: «правильно» или «неправильно». «На почве этого элементарного этического чувства постепенно развивается философская рефлексия, которая уже в античном мире приводит к зарождению идеи так называемого естественного права. Праву действующему и положительному, которое считается продуктом произвольного человеческого установления, противополагается естественное, jus naturale, представляющееся отражением абсолютного разума или правящей миром божественной сущности» [1. С. 61]. В этом смысле средневековая схоластическая догматика права ставила иные вопросы и позиционировала иные ценности. Так, вся земная жизнь человека обесценивалась перед ожидани- ем момента обретения вечного загробного существования.

В эпоху Нового времени антропоцентрическая установка Возрождения была переосмыслена и практически ориентирована на разрешение проблемы гуманистических прав человека, что находит отражение в естественно-правовых доктринах того времени. Если в эпоху итальянского Возрождения подчеркивалась безграничность творческой природы человека, то в сочинениях французских просветителей права на обретение и сохранение жизни, свободу в высказываниях, мнениях и оценках, наличие и защиту собственности, сохранения чести и достоинства, все это возводилось в ранг абсолютных ценностей. Данная ситуация свидетельствовала о том, что принцип гуманизма Ренессанса, заключавшийся в постановке вопроса о достоинстве человека, был перенесен из области философии в сферу права, когда все свободы характеризовались изначальными и безусловными принадлежностями индивида. Более того, наблюдался процесс дистанциирования всего комплекса прав от верховной власти государства, подчеркивалась их первичность по отношению к ней, и даже вводилось ограничение, которое выражалось в том, что государство не имело права посягательства на них. Значение данного подхода в философской и правовой мысли Просвещения заключалось в том, что состоялось формирование гуманистического направления в философском правовом пространстве, которое подчеркивало ценность гуманности в сущности человеческого бытия. Категория естественного права обрела значимый статус мировоззренческой идеи в философско-политической мысли, она подчеркнула связь права с реалиями самой жизни, поэтому гуманистические взгляды стали важным элементом философских трактовок права.

Идея о ценности феномена «естественное право» не была тождественна действующему законодательству, поэтому проблема гуманизации права оставалась открытой. Но процесс углубления юридического содержания права того времени сопровождался включением ряда нравственно-этических оснований, что позволило данной концепции права стать одной из значимых парадигм философско-правового мышления, формировать гуманистически ориентированное правосознание, которое подчеркивало, что нормы естественного права имеют универсальный характер и адресованы всем правоспособным субъектам. Философами-просветителями нормы права толковались как производные элементы естественного миропорядка и 
природы человека, рассматриваемой в качестве микрокосма, позволяя людям связывать индивидуальное существование с всеобщими первоначалами бытия.

Обращение к идеям о ценности и необходимости естественного права и рационального юридического мировоззрения началось с работ Гуго Гроция. В содержании работы «О праве войны и мира» он предложил новый подход, критически переосмысливающий теологический, в рамках которого правовые нормы соотносились с божественной волей. Он обосновал концепцию права естественного и положительного, которое опирается на предписания человеческого разума, способного отчетливо различать справедливость от несправедливости, благо от зла. Как согласующееся с природой вещей, естественное право направлено на благо функционирования любого государства [2. С. 6-7].

Особое внимание Гроций уделял способам доказательства необходимости реализации естественного права, его соответствия как требованиям разумности, так и складывающимся потребностям человеческого общежития. Другое, апостериорное, обусловлено тем, что в своем основании обнаруживает наличие элементов естественного права у всех цивилизованных народов.

Философ отмечал, что наряду с естественноправовыми нормами господствует волеустановленное право, которое представлено гражданскими законами. В них заключена идея существования тех обязательств, которые были приняты людьми добровольно с целью обеспечения всеобщей безопасности. Данное волеустановленное право осуществляет себя в той мере, в какой способно опираться на универсальные основания естественного права, оно выступает как благо и выгода для всех людей, живущих в одном государстве и подчиняющихся его законам [Там же. С. 10-11].

Таким образом, проблема оценки правовой реальности в философской традиции Нового времени была обусловлена разделением права на естественное и позитивное. Это свидетельствовало, с одной стороны, о сложности содержательных характеристик феномена права как некоей целостности, с другой - их расхождение подчеркивало, что в рамках положительного права возможны ситуации нивелирования прав человека. Данное разграничение ориентировало мыслителей того времени на открытие первоначал права в общественной практике, особой природе человеческого существования. Обращаясь к термину «право», отметим, что право ориентирует индивида на обоснованное и определенное поведение, то, которое регламентируется обществом. Тем самым право выступает как утвержденное и осуществляемое в жизненной практике достаточное и признанное основание. В более широком смысле о праве можно говорить как о характеристике определенного поведения и поступков человека, о возможности его свободной самореализации. Отечественный исследователь С.С. Алексеев отмечал в этой связи, что подобное толкование права, отождествляющее его с категорией свободы, находится в одной плоскости с характеристиками самой философии, призванной дать объяснение, обоснование всему сущему [3. С. 412].

Отметим данную проблему, которая с течением времени получит следующее обоснование: философ- ское знание направлено на целостное изучение феномена «право», в то время как само право предписывает границы должного и необходимого. С.С. Алексеев считал, что сложность начинается именно там, где формулируется широкое толкование права, что позволяет не только включить в поле зрения весь спектр бытия, но и обнаружить единство и противодействие двух позиций: прогрессивного и регрессивного толкований дальнейшего развития мира. Именно широкое понимание дефиниции «право», начиная с Античности и до настоящего времени, стало причиной того, что естественное поведение, соответствующее биологической природе человека, стало называться термином «право» [4. С. 6].

Естественное право явилось исходным компонентом целостного и критического исследования природы права, этот тезис может быть объяснен следующим образом: обоснование права, характеризующегося как естественное, актуальное наряду с действующим положительным правом, привело к тому, что основы права стали выявляться из природы реальной жизни. При этом, как отмечали С. Алексеев и И. Покровский, естественное право как методологическая категория стало иметь принципиальное значение, так как обогатило науку того времени социологическими, математическими и другими методами, характеризующими целостный подход к изучению феномена «право». В этом смысле естественное право было направлено на философское осмысление правового пространства, и это основное, что характеризует достоинство данного подхода к оценке многообразия правовых явлений, сводилось к следующему: обнаружить сущностные основания права, выходящие за пределы юридической практики, границы социальнокультурного контекста той или иной эпохи.

Важнейшая установка естественного права была ориентирована на то, что в правовом пространстве обнаруживались не только комплекс правовых норм, получивший отражение в законах позитивного права, но и требования, порожденные самой жизнью, особыми условиями взаимодействия людей, например право первенства. Так, в категории естественного права обнаруживается взаимообусловленность права и явлений общественной жизни, например политического и экономического развития. Мы согласны с позицией ряда авторов, которые полагают, что естественное и позитивное право обнаружили ценность не в процессе построения абстрактных умозрительных конструкций, а в обосновании нового содержания права, которое отражало бы реальные жизненные процессы.

Как справедливо полагал С.С. Алексеев, реальное и явное понимание философского основания права может быть найдено тогда, когда будет применен естественно-правовой подход не только в качестве методологического принципа, но и в качестве онтологического основания. При этом естественные запросы еще не являются правовыми нормами. Прообразами юридических норм выступают требования и правила, совокупность которых характеризует содержание естественного права. «Миссия позитивного права заключается как раз в том, чтобы воплотить в самой 
своей “плоти” органике требования, которые выражены в естественном праве, в прирожденных правах человека» [4. С. 133].

Сформированные естественной средой нормы и правила воспринимались сквозь призму правосознания как некие культурные коды, принимающие правовой облик и юридическое оформление уже в качестве норм позитивного права. И.А. Покровский писал об одной существенной особенности, заключенной в том, что естественное право не может выполнять функции, закрепленные за позитивным правом, например контролировать и давать оценку поступкам людей как основополагающего «критерия юридической правомерности или неправомерности этого поведения, в противном случае ни о законности, ни о верховенстве права в обществе не может быть и речи» [1. С. 57]. Но это не может служить основанием для критики естественного права в качестве общественного регулятора. Те критерии и оценки, которые основаны на повседневных условиях жизни людей, выступают как важнейшая идея позитивного права, его предосновы. Отметим то обстоятельство, что процесс актуализации аксиологического подхода в юридической практике напрямую связан с формированием установок естественного права. Если под содержанием последнего понимать иерархию ценностей «настоящего» права, являющегося образцом и идеалом позитивного права, то естественное характеризуется как важнейшая ценность.

В.С. Нерсесянц полагал, что в содержание понятия «естественное право», наряду с важнейшими правовыми свойствами, «включаются и различные моральные (религиозные, нравственные) характеристики. В результате такого смешения права и морали (религии и т.д.) естественное право предстает как симбиоз различных социальных норм... как некий ценностносодержательный, нравственно-правовой (или - морально-правовой, религиозно-правовой) комплекс, с позиций которого выносится то или иное (как правило негативное) ценностное суждение о позитивном праве и позитивном законодателе (государственной власти)» [5. С. 48-49]. В данном подходе центральное место занимает этическая позиция, рассматривающая естественное право как выражение справедливости и равенства, которому в идеале должно быть тождественно позитивное право, отраженное в законах государства.

После падения наполеоновской империи в центре внимания юристов и философов права оказываются позитивное право, его кодификация, правовое и внеправовое действия, право как социальная институция, имеющая свою историю. Основная посылка философии позитивного права - автономия правового порядка относительно других сфер социальной жизни. Этот поворот к позитивному праву впервые осуществил Гегель. Десятилетие спустя философия права стала общепризнанным полем философского исследования правовых норм и правовой реальности в Германии (Ф.Й. Шталь, А. Лассон), Франции (Э. Лермине), Ж. Удо, В. Белин), Италии (А. Розмини). Весь ХІХ в. прошел по знаменем позитивного права. Надо отметить, что имелись различия в трактовке гражданского общества, которые существовали между сторонника- ми «естественного права» и «позитивного права». Если первые исходили из отождествления «гражданского общества» и политического государства, то вторые подчиняли «гражданское общество» как сферу права, регулирующего экономику, собственность, трудовые отношения.

На рубеже XVIII-XIX вв. происходит размежевание двух систем права - франко-германского нормативного права и англо-американского права прецедента. Это не только две различные судебные системы, но и два способа трактовки правовых норм. Да и понимание «гражданского общества» в этих правовых системах принципиально различно: в праве прецедента акцент делается на правах человека, а в нормативных системах - на приоритете закона, субъектом которого выступает государство.

В начале XX в. становятся явными протестные настроения против метафизики естественного права и позитивного. Не без влияния позитивизма формируется убеждение в том, что юриспруденция нуждается не в философии права, а в общей теории права. Такова позиция Л. Петражицкого и Г. Кельзена, и в наши дни такого рода позиция является популярной. Например, Ф. Эвальд полагал, что всякая система права субъективна и релятивна, поскольку формируется в определенной ситуации, выражает ее и не может мыслиться универсально. Общая теория права должна быть критичной относительно нормативных практических отношений и историчной, фиксируя ситуационную определенность права.

В исторической школе права (Г. Гуго, К.Ф. Савиньи, Г.Ф. Пухта) вообще отрицалось существование естественного права, по их оценкам, оно индивидуально, отражает национальные черты; кроме этого, оно изменяется от одной эпохи к другой. Эти положения дают известное объяснение позитивного права, но не выделяют определяющее, что приводит к пониманию его сущности. Это главное удалось найти И. Канту, развивавшему положения естественного права в формулировку категорического императива: поступай так, чтобы твоя свобода не ограничивала свободу других людей [6. С. 313-314].

Интерпретация естественного права в современной науке специфична. Это во многом обусловлено тем, что в сравнении с эпохой антифеодальных преобразований оформлялся новый взгляд на человека как субъекта и носителя естественных прав. В их перечень стали включать не только неотьемлемые права личности, но и социально-экономические, а также политические. Кроме того, естественное право в этих концептуальных построениях не рассматривалось как совокупность данностей, не подлежащих изменениям. (Р. Штаммлер вводит понятие «естественное право с изменяющимся содержанием»). Метафизический способ толкования пространства права опирался на содержание с ноуменальным, вечным и абсолютным содержанием социально-правовых феноменов, а предметом метафизического познания стали целостность трансцендентной сверхреальности, внутри которой правовая реальность пребывает как один из ее частных модусов. Опираясь на основоположения о Боге, душе и ее бессмертии, которые не могут быть 
верифицируемыми, метафизический метод выступил как главное средство обоснования концепции естественного права, в ценностных установках которого человечество обнаруживало способ приобщения к абсолютным гармоничным установкам бытия. В их свете правопорядок есть малое отражение безграничности вечного, а нормы и ценности права отражают как мир метафизического абсолютного долженствования, так и мир сущего.

В начале XX в. такой подход получил название «возрожденное естественное право», в рамках которого неотомисты Ж. Маритен и В. Катрайн обращались к толкованию естественного закона Фомы Аквинского. Согласно концепции неотомистов, Бог выступает как обладатель абсолютной власти над всеми людьми, а естественный закон есть установленный божественным разумом императив о праве и долге. Так, приобщение человеком к сфере естественного права есть выражение сопричастности к божественной истине. Подчеркивая значение закона, неотомисты полагали, что естественное право раскрывается по мере приближения человека к Богу.

Так, неотомистами была положена собственная классификация прав человека:

- фундаментальные права личности являются естественными, так как обнаруживаются в самой природе человека;

- политические права регламентируются законом, однако подвержены влиянию со стороны естественного права и формируют некое единство;

- социальные права определяют качество и уровень жизни граждан.

Согласно концепции Ж. Маритена, христианский гуманизм Средневековья создал предпосылки для всестороннего развития личности, но к ХХ столетию, когда торжествует «бездуховная цивилизация», Бог «окончательно умер» [7. С. 42-43]. Возможность реформирования общества он связывал с принципами религиозного «интегрального гуманизма». Маритен возлагал надежду на обновление общественной жизни путем утверждения ценностей христианского персонализма, общего блага, плюрализма. Хотя он и выступил задолго до II Ватиканского собора против идей интегризма, им утверждалась необходимость активной деятельности католической церкви по распространению вечных духовных ценностей.

В настоящее время значительное место занимает позиция интегрирования естественного и позитивного права. Так, М.Н. Марченко заявлял о том, что процесс единства должен складываться как путь постепенного наполнения положительного права принципами естественного [8. С. 30]. О.В. Мартышин полагал, «что теория естественного права вполне совместима с анализом системы позитивного права, если верно определить ее место, если рассматривать как идеал. Неразрешимые проблемы возникают тогда, когда естественное право понимается не как идеал, а буквально, т.е. выдается за действующее право. Это создает путаницу» [9. С. 64]. Е.А. Бородин уточнял, что при этом «естественно-правовая концепция не дает определения существа права, а лишь требует от законодателя его сохранения» [10. С. 67].

Таким образом, проблема определения сущности права, роли и значения концепции естественного права остаются открытыми, поэтому выявление онтологического основания данных феноменов посредством гуманизма является актуальным. При этом гуманизм означает совершенствование человеческой природы и воплощение в жизнь идеальных ценностей, и в качестве такового есть сама по себе высшая и самодовлеющая цель человеческой жизни и деятельности. Будучи парадигмой подлинной человечности, гуманизм образует устойчивую связь между конкретными людьми и между поколениями. Несомненно, что за всеми внешними проявлениями, всем тем, чем руководствуется человек в своих правовых действиях, стоят гуманистические ценности и идеалы.

\section{ЛИТЕРАТУРА}

1. Покровский И.А. Основные проблемы гражданского права. М. : Статут, 2009. 351 с.

2. Гуго Гроций. О праве войны и мира. Репринт с изд. 1956. М. : Ладомир, 1994. 868 с.

3. Алексеев С.С. Общая теория права : в 2 т. М. : Юрид. лит., 1981. Т. 1. 361 с.

4. Алексеев С.С. Теория права. М. : БЕГ, 1995. 320 с.

5. Нерсесянц В.С. Общая теория права и государства. М. : Норма: ИНФРА-М, 2012. 560 с.

6. Кант И. Сочинения : в 6 т. М. : Мысль, 1965. Т. 4, ч. І. 544 с.

7. Маритен Ж. Философ в мире. М. : Высш. шк., 1994. 192 с.

8. Марченко М.Н. Основные концепции права и государства в современной России (круглый стол) // Государство и право. 2003. № 5. С. 2832.

9. Мартышин О.В. Метафизические концепции права // Государство и право. 2006. № 2. С. 64-71.

10. Бородин Е.А. Теория «живого права» в системе современного российского правопонимания // Вестник Ивановского государственного университета. Серия: гуманитарные науки. 2014. № 2. С. 64-70.

Статья представлена научной редакцией «Философия» 17 ноября 2017 г.

\section{METAPHYSICAL UNDERSTANDING OF THE DEVELOPMENT OF THE CONCEPT OF NATURAL LAW}

Vestnik Tomskogo gosudarstvennogo universiteta - Tomsk State University Journal, 2017, 425, 100-104. DOI: $10.17223 / 15617793 / 425 / 13$

Veronica I. Miller, Surgut State Pedagogical University (Surgut, Russian Federation). E-mail: econom_law@surgpu.ru Keywords: metaphysics of law; concept of natural law; humanism; human rights.

The article is devoted to the study of the problem of the significance of the concept of natural law in social-philosophical theories and practices. The formation of the concept of natural law is inextricably linked to the Western humanistic tradition. In the era of the New Time, the anthropocentric orientation of the Renaissance was reinterpreted and practically oriented to solve problems of humanistic human rights, which is reflected in the natural law doctrines of the time. The situation testified to the fact that the principle of 
humanism of the Renaissance, which consisted in raising the question of human dignity, moved from the field of philosophy to the field of law. In the Enlightenment, the category of natural law gained a significant status of a philosophical idea in the philosophical and political thought. It stressed the connection of law with the realities of life itself; therefore, humanistic views became an important element of philosophical interpretations of law. At the same time, the idea of the value of the "natural law" phenomenon was not identical to current law; therefore, the problem of the humanization of law remained open. The problem of legal reality assessment in the philosophy of the New Time was due to the division of law into natural and positive. The entire 19th century was under the banner of positive law. The historical school of law denied the existence of natural law, they estimated it individually as the existence of a culture. In the early twentieth century, there were attempts to revive natural law. According to the concept of NeoThomists, God is the possessor of absolute power over all people, and natural law is the imperative of law and duty established by the divine mind. Thus, the communion of man to the sphere of natural law was expressed in belonging to the divine truth. Currently, a significant place is occupied by the position of integration of natural law into positive one. Humanism means improving human nature and bringing ideal values to life and, as such, it is the supreme and self-sufficient purpose of human life and activities. As a paradigm of true humanity, humanism forms a stable bond between individuals and between generations. There is no doubt that behind all the outward manifestations, everything that guides people in their legal actions, there are humanistic values and ideals. Thus, the problem of determining the nature of law, the role and importance of the concept of natural law remains open; therefore, to identify the ontological foundations of these phenomena by means of humanism is relevant.

\section{REFERENCES}

1. Pokrovskiy, I.A. (2009) Osnovnye problemy grazhdanskogo prava [The main problems of civil law]. Moscow: Statut.

2. Hugo Grotius. (1994) O prave voyny i mira [The rights of war and peace]. Translated from Latin. Reprint of the 1956 edition. Moscow: Ladomir.

3. Alekseev, S.S. (1981) Obshchaya teoriya prava: $v 2$ t. [The general theory of law: in 2 volumes]. Vol. 1. Moscow: Yurid. lit.

4. Alekseev, S.S. (1995) Teoriya prava [The theory of law]. Moscow: BEG.

5. Nersesyants, V.S. (2012) Obshchaya teoriya prava i gosudarstva [The general theory of law and the state]. Moscow: Norma: INFRA-M.

6. Kant, I. (1965) Sochineniya: $v 6 t$. [Works: in 6 vols]. Translated from German. Vol. 4. Part 1. Moscow: Mysl'.

7. Maritain, J. (1994) Filosof v mire [Philosopher in the world]. Translated from French. Moscow: Vyssh. shk.

8. Marchenko, M.N. (2003) Osnovnye kontseptsii prava i gosudarstva v sovremennoy Rossii (kruglyy stol) [The main concepts of law and state in modern Russia (round table)]. Gosudarstvo i pravo - State and Law. 5. pp. 28-32.

9. Martyshin, O.V. (2006) Metafizicheskie kontseptsii prava [Metaphysical concepts of law]. Gosudarstvo i pravo - State and Law. 2. pp. 64-71.

10. Borodin, E.A. (2014) The "living law" theory in the system of contemporary Russian understanding of law. Vestnik Ivanovskogo gosudarstvennogo universiteta. Seriya: gumanitarnye nauki. 2. pp. 64-70. (In Russian). 